\title{
Preoperative Lymphedema Education for Breast Cancer Patients
}

\author{
Holly M. Simmons \\ JoAnne Gay Dishman, Department of Nursing, Lamar University, USA
}

Copyright (C) 2015 by authors, all rights reserved. Authors agree that this article remains permanently open access under the terms of the Creative Commons Attribution License 4.0 International License

\begin{abstract}
The purpose of this research study was to determine whether a high level education session with a nurse during the preoperative clinic visit improved the patient's ability to identify signs, symptoms, and risk factors of lymphedema, which is a possible complication related to breast cancer surgery. The study used a pretest posttest descriptive research design. The participant sample included 23 female patients, scheduled to undergo either a sentinel node biopsy or an axillary dissection for their breast cancer. Prior to specific interventions, participants were given a baseline assessment to evaluate current knowledge of lymphedema and to collect demographic data. Post-education assessments were completed immediately after the educational sessions, and again at the participants post-operative clinic visit. Scores from all time points were examined, with the average score on patient surveys improving by nearly $15 \%$ after the education session, indicating that knowledge was retained. The results of the study suggest that a specific nurse guided education session with breast cancer surgery patients during the preoperative visit is effective in improving identification of lymphedema signs, symptoms and risk factors. Additional research into the effects of a continuing education program is warranted to improve upon knowledge retention and self-care practices.
\end{abstract}

Keywords Lymphedema, Education, Breast Cancer

\section{Introduction}

Advancements in treatment regimens for breast cancer patients through clinical research has improved survival and also placed emphasis on maintaining quality of life for breast cancer survivors. Complications associated with breast cancer surgery can affect quality of life for patients, including the risk of developing lymphedema. Lymphedema is caused from a disruption in the lymphatic system from lymph node removal with breast cancer surgery, placing the patient at risk for swelling in the affected arm which can become chronic [12]. Lymphedema is not considered a life-threatening condition and therefore has received less attention in previous studies examining the quality of life of the breast cancer survivor [3]. Many previous studies have focused on identifying the risk factors, signs and symptoms of lymphedema, but more research should focus on preventive practices and education to reduce risks associated with lack of knowledge of lymphedema.

\section{Background}

Research on lymphedema suggests that breast cancer patients will likely develop lymphedema in the initial two to three years post-operatively, but a later onset is still possible for all patients with axillary lymph node removal [10]. Current statistics show approximately $80 \%$ of patients having breast cancer surgery are at risk for lymphedema diagnosis [9]. Breast cancer survivors in multiple studies have reported a lack of pre-operative education in relation to lymphedema, and many say they were not informed of any risk reduction strategies [12]. Recently in our surgical outpatient clinics, patients have indicated that they were not informed of the signs, symptoms or risk factors of lymphedema during their pre or post-operative visits. Thus, an educational intervention is warranted that will help improve upon the patient education process and prevent future complications for patients.

The American Cancer Society (ACS) identified that lymphedema education should follow a three phase education approach that includes pretreatment, postoperative and continuing education [12]. With very few studies related to the implementation of an education program on lymphedema, there is need to identify whether lymphedema education can improve knowledge retention in the pre and post-operative settings. This pilot study was aimed to assess baseline knowledge of lymphedema signs, symptoms and risk factors, and also evaluate the effectiveness of nurse guided education in knowledge retention.

This research study was conducted at a facility classified as one of the national leaders in cancer research. In addition, many breast cancer patients at the facility have access to 
many educational resources and receive neoadjuvant chemotherapy over approximately six months prior to their surgical intervention. Based on these facts, there was an underlying assumption that the patient population would have had some exposure to the topic of lymphedema through multiple modalities, such as support groups, clinicians or the internet prior to participation in the study. It was also assumed that the patients answered all survey questions truthfully, because confidentiality and anonymity were preserved throughout the study. All patients participated voluntarily and had the right to withdraw from the study at any time.

\section{Theoretical Framework}

The Roy Adaptation Model (RAM) is the conceptual framework used in this research project. The RAM identifies that the goal of nursing is to promote adaptation by contributing to health, quality of life and dying with dignity. In this adaptation, the system relationships are enhanced through acceptance, protection and fostering interdependence [14]. Adaptation to change is a process and the outcome involves the person having conscious awareness, that allows for integration between their perceptions and their environment [16]. Once lymphedema education is provided to the patient, the goal is to have the person integrate that knowledge to help identify risk factors and symptoms of the condition.

Orem's Self-Care Theory also helped guide this research, as its major assumption is that people should be knowledgeable of possible health problems or complications in order to develop health promotion behaviors. It also states that nurses must be aware that human beings are both the focus and agents of their own actions [5]. The Self-Care Theory indicates that nursing is a role that encompasses interaction, and by educating patients through one-on-one interactions health prevention can be accomplished. Self-Care Theory works to help the patient achieve a high level of wellness by providing patients with the tools and education they need to be successful. The role of the nurse is to maintain or improve a patient's state of health. Patient education on self-care behaviors allows the patient to be self-reliant and responsible for identifying when new illnesses may exist [6].

\section{Review of Literature}

A literature search was completed using CINAHL and PubMed search engines. Keywords used in the search included "lymphedema prevention", "lymphedema in breast cancer", "lymphedema quality of life", "lymphedema education" and "pretreatment lymphedema education". The search was narrowed by including only articles published after 2000. Abstracts of the articles were then reviewed to identify those that related to lymphedema education in the breast cancer patient population.

The National Cancer Institute (NCI) identifies lymphedema as one of the most poorly understood complications of cancer treatment and should be an important focus for clinicians due to its frequency [9]. Patients with lymphedema experience swelling in the affected limb, skin and pressure changes, including pain from fluid collection in the interstitial space of the tissues [13]. Development of lymphedema can lead to substantial impairment of the affected limb if untreated, which can directly affect the patient's quality of life [1]. Ridner, Dietrich \& Kidd [13] go on to identify that opportunities exist to improve education on lymphedema and a multidisciplinary approach is necessary to improve the quality of life in this population (Table 1).

Table 1. Review of Literature

\begin{tabular}{|c|c|c|c|c|c|}
\hline $\begin{array}{c}\text { Authors/ } \\
\text { Year }\end{array}$ & Population & Hypotheses & Methodology & $\begin{array}{l}\text { Analysis/ } \\
\text { Results }\end{array}$ & Conclusions \\
\hline $\begin{array}{l}\text { Bosompra } \\
\text { et al., } 2001\end{array}$ & $\begin{array}{l}148 \text { post-treatment } \\
\text { breast cancer } \\
\text { patients }\end{array}$ & $\begin{array}{l}\text { Lymphedema education } \\
\text { improves intention to } \\
\text { practice prevention } \\
\text { behaviors }\end{array}$ & $\begin{array}{l}\text { Prospective; } \\
\text { Survey/Telepho } \\
\text { ne Interviews }\end{array}$ & $\begin{array}{l}57.4 \% \text { of respondents cited only } \\
\text { one source of information about } \\
\text { lymphedema }\end{array}$ & $\begin{array}{l}\text { Suggest lymphedema } \\
\text { education is not given } \\
\text { to patients in a timely } \\
\text { fashion. }\end{array}$ \\
\hline $\begin{array}{l}\text { Ridner et } \\
\text { al., } 2010\end{array}$ & $\begin{array}{l}51 \text { breast cancer } \\
\text { patients with } \\
\text { lymphedema }\end{array}$ & $\begin{array}{l}\text { Self-care education } \\
\text { improves self-care } \\
\text { practices and quality of life }\end{array}$ & $\begin{array}{c}\text { Prospective; } \\
\text { Survey }\end{array}$ & $\begin{array}{l}48 \text { patients received some } \\
\text { self-care education; } 18 \text { patients } \\
\text { required help with self-care } \\
\text { activities }\end{array}$ & $\begin{array}{c}\text { Need for improved } \\
\text { lymphedema self-care } \\
\text { education. }\end{array}$ \\
\hline $\begin{array}{l}\text { Bar Ad et } \\
\text { al., } 2012\end{array}$ & $\begin{array}{l}266 \text { Stage I or II } \\
\text { breast cancer } \\
\text { patients with arm } \\
\text { lymphedema }\end{array}$ & $\begin{array}{l}\text { Initial presentation of arm } \\
\text { lymphedema in breast } \\
\text { cancer patients and } \\
\text { potential risk factors }\end{array}$ & $\begin{array}{c}\text { Retrospective; } \\
\text { data analysis }\end{array}$ & $\begin{array}{l}34 \% \text { of patients progressed to a } \\
\text { more severe arm lymphedema } \\
\text { by } 5 \text { years after initial } \\
\text { presentation }\end{array}$ & $\begin{array}{l}\text { Arm lymphedema } \\
\text { results in a reduction of } \\
\text { quality of life. }\end{array}$ \\
\hline $\begin{array}{l}\text { Ridner, } \\
2005\end{array}$ & $\begin{array}{l}149 \text { breast cancer } \\
\text { survivors }\end{array}$ & $\begin{array}{l}\text { Pretreatment education on } \\
\text { lymphedema before after } \\
\text { American Cancer Society } \\
\text { recommendation changes }\end{array}$ & $\begin{array}{l}\text { Prospective; } \\
\text { survey }\end{array}$ & $\begin{array}{l}\text { Participants with lymphedema } \\
\text { recalled receiving less } \\
\text { pretreatment education than } \\
\text { those without lymphedema. }\end{array}$ & $\begin{array}{l}\text { Quality pretreatment } \\
\text { lymphedema education } \\
\text { can improve patient } \\
\text { outcomes. }\end{array}$ \\
\hline $\begin{array}{l}\text { Sherman \& } \\
\text { Koelmeyer, } \\
2012\end{array}$ & $\begin{array}{l}98 \text { recently } \\
\text { diagnosed breast } \\
\text { cancer patients }\end{array}$ & $\begin{array}{l}\text { Psychological influence on } \\
\text { adherence to risk } \\
\text { management strategies }\end{array}$ & $\begin{array}{l}\text { Prospective; } \\
\text { survey }\end{array}$ & $\begin{array}{l}\text { Patients had greater adherence } \\
\text { to risk management strategies } \\
\text { with greater knowledge }\end{array}$ & $\begin{array}{l}\text { A woman informed } \\
\text { and knowledgeable } \\
\text { about their risk will } \\
\text { utilize risk reduction } \\
\text { strategies. }\end{array}$ \\
\hline
\end{tabular}

$[3,13,2,12,15]$ 


\section{Methodology}

This pilot study used a descriptive design with a purposive sample of patients who were scheduled for sentinel lymph node biopsy or axillary dissection for their breast cancer. All patients who agreed to participate completed a pretest survey collecting demographic information, and to assess their prior knowledge on lymphedema. All participants received an optimal educational intervention, which included a patient handout and a seven minute lymphedema video [4]. The patients completed post-education surveys immediately after the educational session, and again at their first post-operative visit. The nurse researcher conducted all education sessions to ensure continuity of information disseminated and improve reliability of results. During all visits with the patients, opportunity was given to ask questions before and after the educational intervention. The study took place over a 12 week period, during normal clinic operations.

\section{Subject Selection and Description}

Inclusion criteria involved: female patients who were English speaking and reading, were 18 years of age or older, and were scheduled for either axillary lymph node dissection or sentinel lymph node biopsy with their breast cancer surgery. Exclusion criteria involved: males, or females who were below 18 years of age, did not speak or read English, and those not scheduled for a node dissection or sentinel lymph node biopsy with their breast cancer surgery.

Once institutional review board approval was received from both Lamar University and the treating facility, eligible patients were approached for participation. Patients were presented with the study objectives and those willing to participate completed the informed consent during their pre-operative visit. Participants were accrued from approximately five different surgeon clinics and a total of 24 eligible patients were consented. One patient cancelled their planned surgery, therefore a total of 23 participants were evaluated.

An accrual of 23 represents $35 \%$ of the at risk surgical population in the outpatient clinic over one calendar month. With nearly 80 patients scheduled for surgery every month, approximately 64 of those patients were at risk for development of lymphedema based on current data. On average, each breast cancer surgeon in our facility operates on 15 patients per month. Approximately half of those patients had an axillary lymph node dissection or a sentinel lymph node biopsy with their breast surgery.

\section{Instrumentation}

The survey instrument was developed from a review of current literature on lymphedema signs, symptoms, and risk factors. Expert nurses reviewed the pretest and posttest questions (Appendix A) to establish validity. The pretest survey included demographic data, and identification of the type of surgical intervention. The lymphedema specific questions were the same for both the baseline survey and the post-education surveys completed after the educational intervention and at the post-operative visit. All questions on the surveys were multiple choice. The post-education surveys included two additional questions to evaluate effectiveness of the educational plan and whether outside education resources were used by the patient. This is the first time the survey instrument was given; therefore reliability has not been established for the data collection instrument.

\section{Data Collection Procedures and Data Entry}

The surgical clinics were screened to identify eligible patients in the pre-operative setting. Those eligible patients were approached for participation at the pre-operative clinic visit. Patients that agreed to participate completed the informed consent document (Appendix B). After consent was obtained, participants were assigned an identification number and then completed the baseline survey. The nurse then discussed the lymphedema educational handout with the patient and showed a 7-minute lymphedema video. A suggestion was made to take notes as desired, and time was allowed to ask questions after the education session for clarification as needed.

Immediately after the educational sessions with the nurse, the patients completed the post-education survey during the pre-operative visit. Approximately 1-3 weeks later at the patient's post-operative visit, the participants completed the post-education survey again to evaluate knowledge retention and effectiveness of educational approach. To maintain anonymity and protect patient identity, all patients were given participant identification numbers. Scores from the baseline survey and the two post-education surveys were compared on each participant to determine if the teaching methods were effective.

\section{Data Analysis}

All data was analyzed using the Statistical Package for Social Sciences (SPSS) version 22 software [7]. Frequency distributions were used to summarize nominal and ordinal variables. Means, ranges and standard deviation were used to evaluate scores on pre and post education surveys. Frequency data was calculated to evaluate the two additional questions in the post-education surveys. Pearson's $r$ was used to determine correlations between education level and survey scores.

\section{Results}

The average age of participants was 50.70 , with the 
youngest participant aged 30 and the oldest aged 76 years. All respondents underwent surgery during the 12 week period of data collection, with most having a sentinel node biopsy $(78.3 \%, \mathrm{n}=18)$. Most of the participants were of Caucasian ethnicity $(65.2 \%, \mathrm{n}=15)$, married $(65.2 \%, \mathrm{n}=17)$, lived with their spouse $(39.1 \%, \mathrm{n}=9)$ and employed full-time $(52.2 \%, \mathrm{n}=12)($ Table2).

Table 2. Survey respondent demographics

\begin{tabular}{|c|c|}
\hline Variable & $\%(n=23)$ \\
\hline \multicolumn{2}{|l|}{ Ethnicity } \\
\hline Asian & $8.7(2)$ \\
\hline African-American & $4.3(1)$ \\
\hline Caucasian & $65.2(15)$ \\
\hline Hispanic & $21.7(5)$ \\
\hline \multicolumn{2}{|l|}{ Marital Status } \\
\hline Single & $17.4(4)$ \\
\hline Married & $73.9(17)$ \\
\hline Divorced & $8.7(2)$ \\
\hline \multicolumn{2}{|l|}{ Level of Education } \\
\hline High School & $34.8(8)$ \\
\hline College Degree & $30.4(7)$ \\
\hline Graduate Degree & $30.4(7)$ \\
\hline \multicolumn{2}{|l|}{ Employment Status } \\
\hline Full time & $52.2(12)$ \\
\hline Part time & $13.0(3)$ \\
\hline Unemployed & $4.3(1)$ \\
\hline Student & $4.3(1)$ \\
\hline Retired & $26.1(6)$ \\
\hline \multicolumn{2}{|l|}{ Living Situation } \\
\hline Lives alone & $13.0(3)$ \\
\hline Lives with spouse & $39.1(9)$ \\
\hline Lives with spouse $\&$ children & $34.8(8)$ \\
\hline Other & $13.0(3)$ \\
\hline \multicolumn{2}{|l|}{ Type of Surgery } \\
\hline Axillary node dissection & $21.7(5)$ \\
\hline Sentinel node biopsy & $78.3(18)$ \\
\hline
\end{tabular}

Results from baseline surveys show that participants' first exposure to the topic of lymphedema came from doctors $(30.4 \%, \mathrm{n}=7)$, nurses $(21.7 \%, \mathrm{n}=5)$, a friend or family member $(26.1 \%, \mathrm{n}=6)$ or some other information source such as books, magazines, television or the internet $(21.7 \% \mathrm{n}=5)$. The majority of patients indicated that they had recently learned about lymphedema within the last year $(68.2 \%$, $\mathrm{n}=15)$, while 5 patients $(21.7 \%)$ stated they had exposure to lymphedema education more than 5 years ago. In evaluation of the individual questions related to lymphedema signs and symptoms, most patients $(91.3 \%, \mathrm{n}=21)$ could define the term lymph node, the definition of lymphedema $(91.3 \%$, $\mathrm{n}=21$ ), and that swelling in the hands, fingers and arms was a sign of lymphedema $(100 \%, n=23)$. Survey item number 5 relating to what can be done to reduce risk was answered incorrectly by $11(47.8 \%)$ of the participants, with five patients $(21.7 \%)$ not providing an answer.

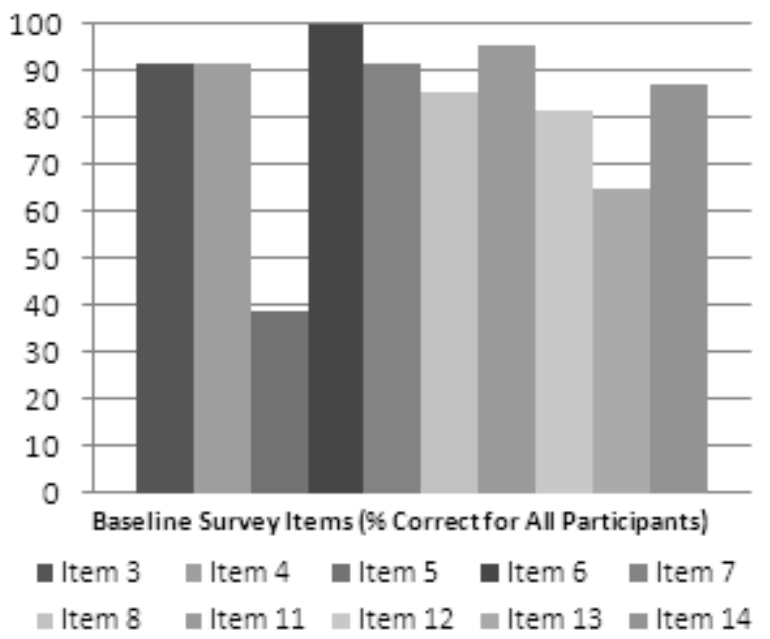

Figure 1. Bar graph of percentages of correctly answered items from the baseline survey administered.

After the educational intervention, the first post education surveys showed that the education improved participant identification of lymphedema risk factors. On survey item number five, the patient responses improved from 30.4\% $(\mathrm{n}=7)$ of participants responding correctly at baseline to $87.0 \%(\mathrm{n}=20)$ after the educational intervention (Figure 2). In addition, on survey items seven and eight $95.7 \%(\mathrm{n}=22)$ answered the questions correctly which showed an improvement of $4.4 \%$ and $17.4 \%$, respectively. After education, more patients were able to identify that a compression sleeve $(100 \%, n=23)$, exercises of the hand/arm $(91.3 \%, \mathrm{n}=21)$ and Manual Lymphatic Drainage $(73.9 \%$, $\mathrm{n}=17$ ) were treatments available for lymphedema.

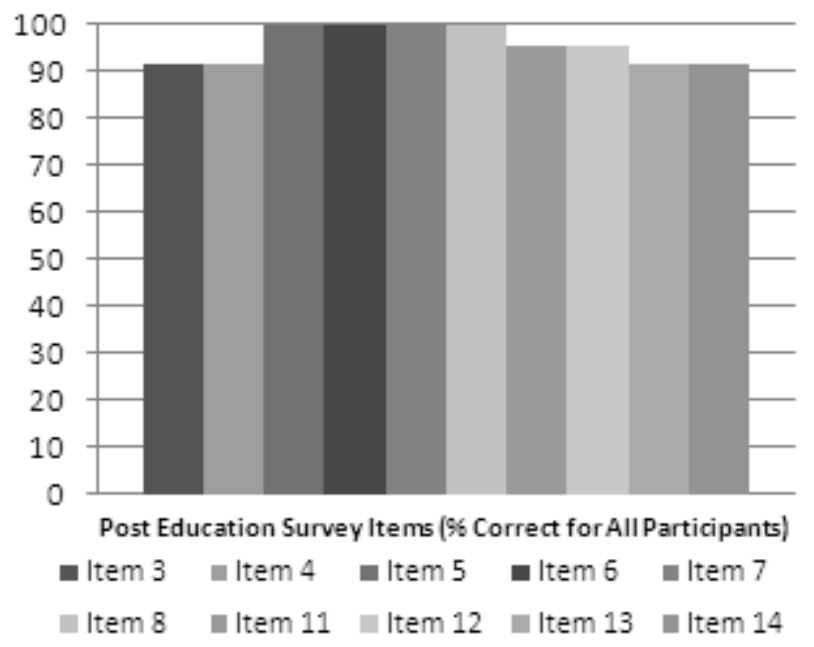

Figure 2. Bar graph of percentages for correctly answered items from the first post-education survey administered.

When the patients returned for their post-operative visits, the post-education surveys completed at that time point showed that the knowledge was retained in many areas, but 
also showed some areas of decline. Specifically, the number for patients responding correctly to item $5(87 \%, \mathrm{n}=20)$ and item $13(78.3 \%, n=18)$ decreased at the post-operative visit evaluation (Figure 3). Despite the declines on those two items, improvements in response to items 3, 7, 8, 11 and 12 indicate that the teaching provided on lymphedema risk factors, signs and symptoms was retained and integrated. The two post education surveys show that respondents utilized additional resources to learn about lymphedema after the educational intervention. Patients used the internet $(60.9 \%, n=14)$ and support groups $(13 \%, n=3)$ primarily to obtain additional information on lymphedema, while there were still $30.4 \%(n=7)$ of patients who did not seek further information.

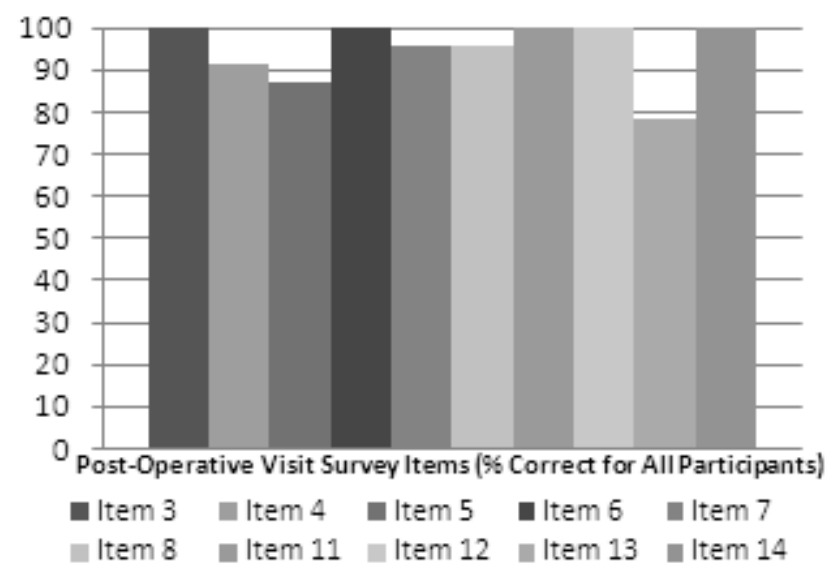

Figure 3. Bar graph of percentages for correctly answered items from the second post-education survey administered.

In review of the overall scores on the surveys of participants, the mean scores and standard deviation at baseline was $80.86 \pm 16.76$, immediately post educational intervention was $95.21 \pm 8.46$, and at the post-operative visits were $94.78 \pm 6.65$ (Table 3 ). There was no correlation found in comparing the patient's highest level of education and their baseline survey scores $(r=0.104, n=22, p=0.644)$.

Table 3. Descriptive statistics of participant survey scores.

\begin{tabular}{ccccc}
\hline & N & Range & Mean & Std. Deviation \\
\hline Baseline Score & 23 & 60.00 & 80.86 & 16.76 \\
Post-Education Score & 23 & 30.00 & 95.21 & 8.45 \\
Post-Operative Score & 23 & 20.00 & 94.78 & 6.65 \\
\hline
\end{tabular}

The final two questions on both post education surveys assessed whether patients felt they benefitted from the educational intervention, and if they utilized additional information sources for lymphedema information. All patients $(100 \%, \mathrm{n}=23)$ felt the information provided was beneficial, and most patients indicated they had acquired additional information on lymphedema using multiple resources (Table 4). Patients were able to identify that they should notify a nurse $(65.2 \%, \mathrm{n}=15)$, a physician $(91.3 \%$, $n=21)$ or a physical therapist $(69.6 \%, n=16)$ if they experience symptoms related to lymphedema.
Table 4. Participant use of additional information sources.

\begin{tabular}{cc}
\hline Informational Source & $\%(\mathrm{n})$ \\
\hline Internet & $60.9(14)$ \\
Books & $4.3(1)$ \\
Journal Articles & $8.7(2)$ \\
Support Group & $13.0(3)$ \\
\hline Lymphedema Specialist & $4.3(1)$ \\
Consultation & $4.3(1)$ \\
\hline
\end{tabular}

\section{Discussion \& Practice Implications}

The results of the study indicate that a nurse guided lymphedema education session with patients in the preoperative setting improves patient recognition of signs, symptoms and risk factors of the condition. The assumption that patients would have prior knowledge on lymphedema proved to be true with a mean baseline survey score of 80.86 \pm 16.76 , but the data shows that with additional education the overall patient score improved. This study did not evaluate long-term outcomes of the educational intervention; therefore additional research could help substantiate these results.

All patients completing the surveys felt the educational intervention was beneficial and the education session improved upon the process for educating patients in the pre-operative setting. A primary goal in post-operative care plan is to have the patient take an active role in their recovery and self-care maintenance after breast cancer surgery. Taking a multidisciplinary approach to educating the patient meets the standards set forth by the American Cancer Society, and also provides the patient with education in advance to allow time for integration into their daily practices [11].

An important finding from this research shows that only 13 of the $23(52.1 \%)$ patients surveyed indicated that their first exposure to the topic of lymphedema was from discussion with a medical professional (doctor or nurse). As healthcare providers, informing patients of risks and side effects from treatment are a primary responsibility and these results show there is room for improvement in our patient education practices. Oftentimes, patients seeking information from outside sources such as the internet or social media can be misinformed of their risk. It is important that the treating practitioners work to provide factual data regarding risk reduction strategies.

As noted previously, ACS states that lymphedema education should be included in pretreatment, postoperative and continuing education [11]. In review of the post-operative visit survey scores; it is evident that more effort is required in continuing these education efforts for risk reduction strategies in breast cancer surgical patients. Although overall scores were improved compared to baseline, there was a slight decline in patient identification of risk factors of lymphedema at the postoperative visit. 
Therefore, additional studies should evaluate the effectiveness of continuing education plans as well.

Although many of our patients are educated about lymphedema and may have some prior knowledge, it is the responsibility of the care providers to make sure the patient is receiving current and factual information to improve the patient's self-reliance and self-care practices. Utilizing a nurse-guided education plan with patients can help provide quick factual information to the patient without disrupting the clinic flow.

\section{Conclusions}

The study cannot be generalized to other similar organizations because of the small sample size of 23 participants. Due to the time limitations of this 12-week study, and access to limited numbers of patients, additional intervals for knowledge retention assessment could not be completed to evaluate long-term outcomes of the educational intervention. Lastly, the descriptive design of the study does not allow for comparison of a control group and an experimental group to evaluate the teaching methods used.

The results of the research study were successful in that a special nurse guided education session and video on lymphedema during the pre-operative visit improved the patient's knowledge of lymphedema risk factors, signs and symptoms related to their breast cancer surgery. The results indicate that additional research could be beneficial in evaluating additional educational interventions, as well as finding the benefit of a nurse guided educational plan in the postoperative setting, and assessing ways of providing continued education. The data collected indicates a need for a multidisciplinary approach to patient education in our breast clinics and signifies the importance of communicating factual and useful information to the patients. Discussion and collaboration between the team of healthcare providers is imperative to ensure patients are knowledgeable and prepared to have in active role in their long-term care after breast cancer surgery.

\section{Appendix A}

\section{Pretest and Posttest for all participants in the study.}

Participant ID:

\section{Baseline Demographics}

Age:

Gender: $\quad$ Male Female

Race (circle one): Caucasian African-American Asian Biracial Hispanic Other

Highest Level of Completed Education (circle one):

\section{Elementary School \\ College Degree}

Marital Status (circle one):

Job Status (circle one):

Student

\author{
High School \\ Graduate Degree
}

$$
\text { Single } \quad \text { Married Divorced }
$$

Employed Full Time Employed Part Time Unemployed

$$
\text { Retired }
$$

Living Situation (circle one): Live alone Live with spouse Live with spouse $\&$ children

Live with children Other

Which type of surgery are you scheduled for (select one)?

Axillary Lymph Node Dissection (removal of all axillary lymph nodes)

Sentinel Lymph Node Biopsy (removal of a few axillary lymph nodes) 
Participant ID:

\section{Baseline Lymphedema Knowledge Assessment}

Circle your answers for all questions and initial/date once completed.

1. How did you first learn about lymphedema?
a. Doctor
b. Nurse
c. Friend/Family
d. Information source (magazine, TV, book, etc.)

2. How long ago did you learn about lymphedema?
a. Less than a year ago
b. One to two years ago
c. Three to four years ago
d. More than five years ago

3. What are lymph nodes?
a. Small sac-like structures found all over the body
b. Bony growths around the long bones in the arms
c. The place where blood cells are made
d. Benign tumors in the abdomen

4. What is lymphedema?
a. Arthritis that only affects breast cancer patients.
b. Fluid collecting in the arm or hands that causes swelling.
c. A condition that can be cured and is treated easily.
d. An infection that occurs anywhere in the body.

5. Which of the following can be done to reduce the risk of lymphedema?
a. Try to lift heavy objects to build muscles
b. Always have blood taken from the same side as surgery.
c. Wear gardening gloves when doing yard work
d. Taking a multivitamin daily

6. What is a sign and symptom of lymphedema?
a. A rash that extends to the chest
b. Swelling in the hands, fingers or arm
c. Muscle spasms in the back or leg
d. Loss of muscle tone and weakness

7. Which of the following is TRUE about lymphedema?
a. Lymphedema is a genetic condition
b. Lymphedema is a condition that can be cured
c. Lymphedema can occur at any point after surgery
d. Lymphedema affects the entire body

8. Who is most at risk for developing lymphedema?

a. Patients having an allergic reaction to a medication. 
b. Patients who smoke or have smoked.

c. Patients who exercise regularly.

d. Patients who have had a large number of lymph nodes removed during surgery.

9. Circle all items that are treatments available for lymphedema:
a. Compression sleeves
b. Prescribed medications
c. Exercises of the hand/arm
d. A special massage called Manual Lymphatic Drainage

10. During your visits with the surgeon, who spoke to you about lymphedema? (Circle all that apply)
a. Surgeon
b. Nurse
c. Nurse Assistant
d. Physician's Assistant or Nurse Practitioner

11. Which of the following areas help treat patients with lymphedema?
a. Radiation Oncology
b. Physical Therapy
c. Medical Oncology
d. Nutritional Therapy

12. What treatment is used for lymphedema?
a. Medication to reduce symptoms
b. There is no treatment available currently
c. Compression sleeves or garments
d. Indwelling drainage catheters

13. Lymphedema patients should NOT do the following?
a. Wear gloves while washing the dishes
b. Exercise regularly and maintain weight
c. Use a moisturizer daily
d. Take hot baths regularly

14. When can lymphedema develop in patients after surgery?
a. Within 6 months after surgery
b. Within one to two years after surgery
c. Within two to five years after surgery
d. At any time after surgery

15. Who should a patient talk to if they think they may have lymphedema? (Circle all that apply)
a. Social worker
b. Doctor
c. Nurse
d. Physical Therapist 
Participant ID:

\section{Post Education Assessment}

Circle your answers for all questions and initial/date once completed.

1. How did you first learn about lymphedema?
a. Doctor
b. Nurse
c. Friend/Family
d. Information source (magazine, TV, book, etc.)

2. How long ago did you learn about lymphedema?
a. Less than a year ago
b. One to two years ago
c. Three to four years ago
d. More than five years ago

3. What are lymph nodes?
a. Small sac-like structures found all over the body
b. Bony growths around the long bones in the arms
c. The place where blood cells are made
d. Benign tumors in the abdomen

4. What is lymphedema?
a. Arthritis that only affects breast cancer patients.
b. Fluid collecting in the arm or hands that causes swelling.
c. A condition that can be cured and is treated easily.
d. An infection that occurs anywhere in the body.

5. Which of the following can be done to reduce the risk of lymphedema?
a. Try to lift heavy objects to build muscles
b. Always have blood taken from the same side as surgery.
c. Wear gardening gloves when doing yard work
d. Taking a multivitamin daily

6. What is a sign and symptom of lymphedema?
a. A rash that extends to the chest
b. Swelling in the hands, fingers or arm
c. Muscle spasms in the back or leg
d. Loss of muscle tone and weakness

7. Which of the following is TRUE about lymphedema?
a. Lymphedema is a genetic condition
b. Lymphedema is a condition that can be cured
c. Lymphedema can occur at any point after surgery
d. Lymphedema affects the entire body 
8. Who is most at risk for developing lymphedema?

a. Patients having an allergic reaction to a medication.

b. Patients who smoke or have smoked.

c. Patients who exercise regularly.

d. Patients who have had a large number of lymph nodes removed during surgery.

9. Circle all items that are treatments available for lymphedema:

a. Compression sleeves

b. Prescribed medications

c. Exercises of the hand/arm

d. A special massage called Manual Lymphatic Drainage

10. During your visits with the surgeon, who spoke to you about lymphedema? (Circle all that apply)
a. Surgeon
b. Nurse
c. Nurse Assistant
d. Physician's Assistant or Nurse Practitioner

11. Which of the following areas help treat patients with lymphedema?
a. Radiation Oncology
b. Physical Therapy
c. Medical Oncology
d. Nutritional Therapy

12. What treatment is used for lymphedema?
a. Medication to reduce symptoms
b. There is no treatment available currently
c. Compression sleeves or garments
d. Indwelling drainage catheters

13. Lymphedema patients should NOT do the following?
a. Wear gloves while washing the dishes
b. Exercise regularly and maintain weight
c. Use a moisturizer daily
d. Take hot baths regularly

14. When can lymphedema develop in patients after surgery?
a. Within 6 months after surgery
b. Within one to two years after surgery
c. Within two to five years after surgery
d. At any time after surgery

15. Who should a patient talk to if they think they may have lymphedema? (Circle all that apply)
a. Social worker
b. Doctor
c. Nurse
d. Physical Therapist 
16. Do you feel the lymphedema education you were given today was beneficial?

a. Yes

b. No (if no, explain):

17. Have you used any other formats to learn about lymphedema? (circle those that apply)
a. Internet
b. Books
c. Journal Articles
d. Support Group
e. Lymphedema Specialist consultation
f. Physical Therapist consultation
g. None

\title{
Appendix B
}

\author{
Sample Informed Consent
}

\section{Informed Consent}

\section{INFORMED CONSENT/AUTHORIZATION FOR PARTICIPATION IN RESEARCH}

The Effect of Pre and Post-Operative Lymphedema Education for Breast Cancer Patients Having Axillary Node Dissection or Sentinel Lymph Node Biopsy

PA14-0906

\section{Study Chair: Holly M. Simmons}

1.

Participant's Name

Medical Record Number

You are being asked to take part in this data review research study at this treatment facility. This consent and authorization form explains why this research study is being done and what your role will be if you choose to take part. This form also describes the possible risks connected with being in this study. After reviewing this information with the person responsible for your enrollment, you should know enough to be able to make an informed decision on whether you want to take part in the study.

You are being asked to take part in this study because you are scheduled to have either an axillary lymph node dissection or sentinel lymph node biopsy for breast cancer.

DESCRIPTION OF RESEARCH

\section{PURPOSE OF STUDY}


The goal of this research study is to identify standards for best practice in educating patients about the risk factors, signs, and symptoms of lymphedema before and after breast cancer surgery.

\section{DESCRIPTION OF STUDY}

If you agree to take part in this study, you will complete a questionnaire that asks about your age, race, gender, and other basic information. Then you will complete a questionnaire that tests your knowledge of lymphedema.

You will then be given a handout on lymphedema that the nurse researcher will discuss with you and answer any questions you may have.

You will then view a 7-minute video on lymphedema risk factors, signs, symptoms and treatment. After that, you may ask questions to the nurse researcher and will be provided the nurse's contact information if you have further questions after the visit. After all education modules have been covered you will be given a questionnaire that asks about your knowledge of lymphedema.

At your visit following your surgery you will be given the same questionnaire that asks about your knowledge of lymphedema.

All questionnaires should take about 15 minutes to complete each time.

This is an investigational study. There will be no cost to you for taking part in this study.

Up to 25 participants will be enrolled in this study. All will be enrolled at this treatment facility.

\section{RISKS, SIDE EFFECTS, AND DISCOMFORTS TO PARTICIPANTS}

You should discuss the risks of questionnaires with the study chair. The known risks are listed in this form, but they will vary from person to person. Some questions may make you feel upset or uncomfortable. You may refuse to answer any question. If you have concerns after completing the questionnaires, you are encouraged to contact your doctor or the study chair.

Although every effort will be made to keep study data safe, there is a chance that your personal health information could be lost or stolen. All study data will be stored in password-protected computers and/or locked file cabinets. There will be no personal identifying information connected to your questionnaire answers. The study data will be destroyed 5 years after the study has been published.

This study may involve unpredictable risks to the participants.

\section{POTENTIAL BENEFITS}

You may learn more about lymphedema risk factors, signs, and symptoms. Future patients may benefit from what is learned. There may be no benefits for you in this study.

\section{ALTERNATIVE PROCEDURES OR TREATMENTS}

You may choose not to take part in this study.

\section{$\underline{\text { Additional Information }}$}

7. You may ask the study chair any questions you have about this study. You may contact the study chair, Dr. Holly M. Simmons, at 713-792-6491. You may also contact the Chair of the Institutional Review Board (IRB - a committee that reviews research studies) at 713-792-2933 with any questions that have to do with this study or your rights as a study participant.

8. Your participation in this research study is strictly voluntary. You may choose not to take part in this study without any penalty or loss of benefits to which you are otherwise entitled. You may also withdraw from participation in this study at any time without any penalty or loss of benefits. If you withdraw from this study, you can still choose to be treated at this facility.

9. This facility may benefit from your participation and/or what is learned in this study. 
If you suffer injury as a direct result of taking part in this study, The facility health providers will provide medical care. However, this medical care will be billed to your insurance provider or you in the ordinary manner. You will not be reimbursed for expenses or compensated financially by the institution for this injury. You may also contact the Chair of the IRB at 713-792-2933 with questions about study-related injuries. By signing this consent form, you are not giving up any of your legal rights.

You will receive no compensation for taking part in this study.

Authorization for Use and Disclosure of Protected Health Information:

A. During the course of this study, the research team at the institution will be collecting and using your protected health information. This information may include personal identifying information about you (such as your race, age, gender, educational level, marital status, job status and living situation), your surgery schedule, and your surgical follow up schedule. The purpose of collecting and sharing this information is to help researchers to link their laboratory findings with clinical information and/or outcome data in an effort to learn about the effects of lymphedema education in breast cancer patients. Your doctor and the research team may share your study information with the parties named in Section D below. B. Signing this consent and authorization form is optional. However, if you refuse to provide authorization to use and disclose your protected health information for this study, you will not be able to participate in this research study.

C. The institution will take appropriate steps to keep your protected health information private when possible, and it will be protected according to state and federal law. However, there is no guarantee that your information will remain confidential, and it may be re-disclosed at some point. Federal agencies (such as the U.S. Food and Drug Administration [FDA], the Office for Human Research Protections [OHRP - a regulatory agency that oversees research in humans], or National Cancer Institute [NCI]), and the IRB might view or receive your record in order to collect data and/or meet legal, ethical, research, and safety-related obligations. In some situations, the FDA could be required to reveal the names of participants.

D. Your protected health information may be shared with the following parties:

- Lamar University Graduate Advisor - Dr. Tess Pape

- Federal agencies that require reporting of clinical study data (such as the FDA, NCI, and OHRP)

- The IRB of the institution.

- Officials of institution.

- Clinical study monitors who verify the accuracy of the information

- Individuals with medical backgrounds who determine the effect that the study procedures may have on the disease

- Individuals who put all the study information together in report form

E. There is no expiration date for the use of your protected health information. You may withdraw your authorization to share your protected health information at any time in writing. Instructions on how to do this can be found in the institutional Notice of Privacy Practices (NPP). You may contact the IRB Staff at 713-792-2933 with questions about how to find the NPP. If you withdraw your authorization, you will be removed from the study and the study chair and staff will no longer use or disclose your protected health information in connection with this study, unless the study chair or staff needs to use or disclose some of your research-related protected health information to preserve the scientific value of the study. Data collected about you up to the time you withdrew will be used and included in the data analysis. The parties listed in Section D above may use and disclose any study data that were collected before you canceled your authorization.

\section{CONSENT/AUTHORIZATION}

I understand the information in this consent form. I have had a chance to read the consent form for this study, or have had it read to me. I have had a chance to think about it, ask questions, and talk about it with others as needed. I give the study chair permission to enroll me on this study. By signing this consent form, I am not giving up any of my legal rights. I will be given a signed copy of this consent document. 


\section{RELATIONSHIP TO PARTICIPANT}

\section{WITNESS TO CONSENT}

I was present during the explanation of the research to be performed under Protocol PA14-0906.

SIGNATURE OF WITNESS TO THE VERBAL CONSENT PRESENTATION

DATE (OTHER THAN PHYSICIAN OR STUDY CHAIR)

A witness signature is only required for vulnerable adult participants. If witnessing the assent of a pediatric participant, leave this line blank and sign on the witness to assent page instead.

\section{PERSON OBTAINING CONSENT}

I have discussed this research study with the participant and/or his or her authorized representative, using language that is understandable and appropriate. I believe that I have fully informed this participant of the nature of this study and its possible benefits and risks and that the participant understood this explanation.

\section{TRANSLATOR}

I have translated the above informed consent as written (without additions or subtractions) into

(Name of Language) and assisted the people

obtaining and providing consent by translating all questions and responses during the consent process for this participant.

NAME OF TRANSLATOR

SIGNATURE OF TRANSLATOR

DATE

Please check here if the translator was a member of the research team. (If checked, a witness, other than the translator, must sign the witness line below.) 


\section{Appendix C}

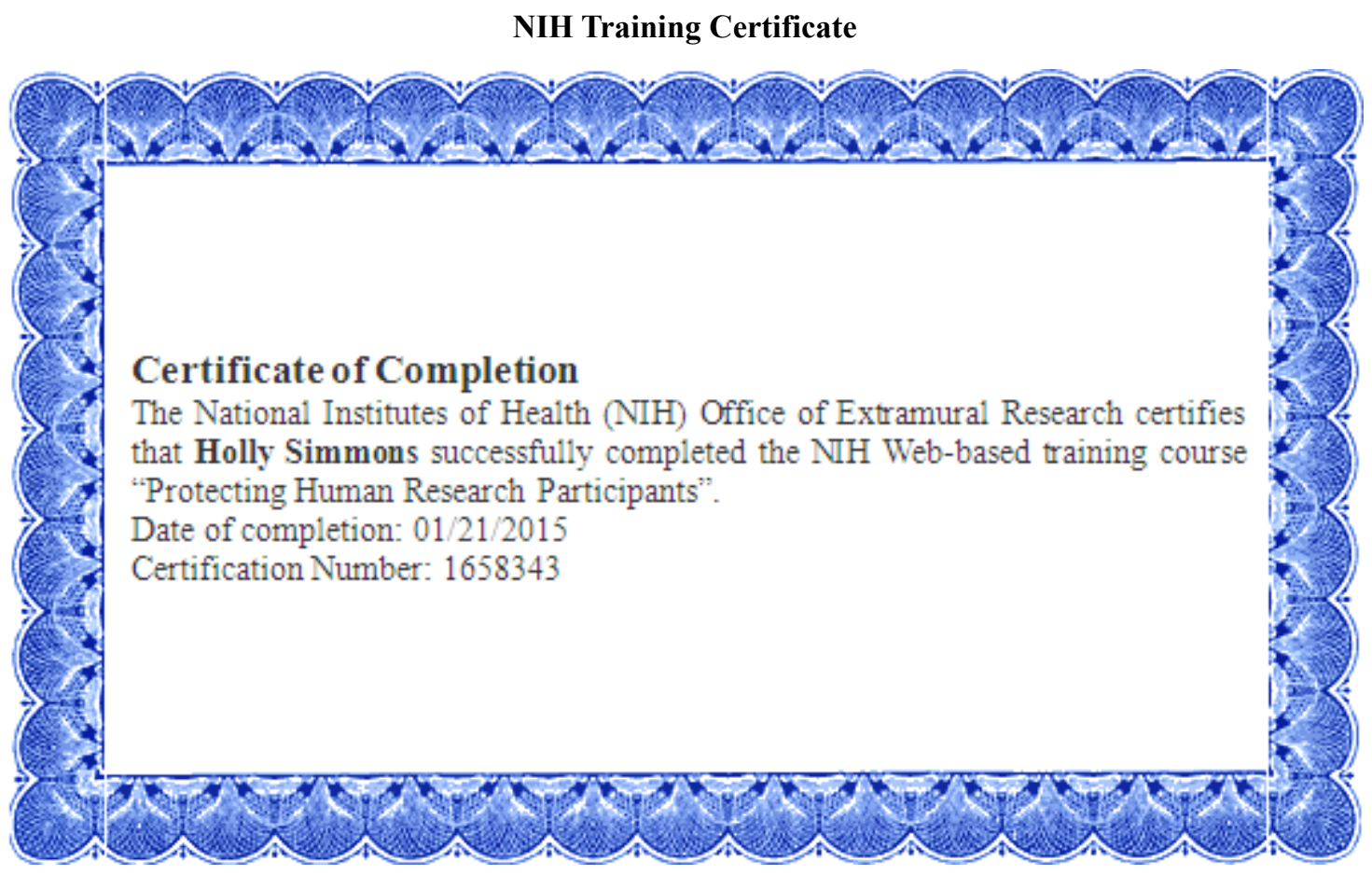

\section{REFERENCES}

[1] Bani H, Fasching P, Lux M, Rauh C, Willner M, Eder I et al. Lymphedema in breast cancer survivors: Assessment and information provision in a specialized breast unit. Patient Education and Counseling. 2007;66(3):311-318.

[2] Bar Ad V, Dutta P, Solin L, Hwang W, Tan K, Both S et al. Time-Course of Arm Lymphedema and Potential Risk Factors for Progression of Lymphedema After Breast Conservation Treatment for Early Stage Breast Cancer. The Breast Journal. 2012;18(3):219-225.

[3] Bosompra K, Ashikaga T, Oâ€ $€^{\mathrm{TM} B r i e n ~ P, ~ N e l s o n ~ L, ~ S k e l l y ~ J, ~}$ Beatty D. Knowledge about preventing and managing lymphedema: a survey of recently diagnosed and treated breast cancer patients. Patient Education and Counseling. 2002;47(2):155-163.

[4] CancerQuest $\mid$ A Cancer Education Resource. CancerQuest Breast Cancer Videos and Animations [Internet]. 2015 [cited 2013]. Available from: http://www.cancerquest.org/breast-cancer-videos.html

[5] Denyes M, Orem D, Bekel G. Self-Care: A Foundational Science. Nursing Science Quarterly. 2001;14(1):48-54.

[6] Hartweg D. Health promotion self-care within Orem's general theory of nursing. J Adv Nurs. 1990;15(1):35-41.

[7] IBM Corp. Released 2013. IBM SPSS Statistics for Windows, Version 22.0. Armonk, NY: IBM Corp.

[8] Iom.edu. From Cancer Patient to Cancer Survivor: Lost in Transition - Institute of Medicine [Internet]. 2015. Available from:

http://www.iom.edu/Reports/2005/From-Cancer-Patient-toCancer-Survivor-Lost-in-Transition.aspx

[9] National Cancer Institute. Lymphedema [Internet]. 2015 [cited 2015]. Available from: http://www.cancer.gov/cancert opics/pdq/supportivecare/lymphedema/healthprofessional/pa ge1

[10] Nielsen I, Gordon S, Selby A. Breast cancer-related lymphoedema risk reduction advice: A challenge for health professionals. Cancer Treatment Reviews. 2008;34(7):621-628.

[11] Polit D, Beck C. Nursing research. 8th ed. Philadelphia: Wolters Kluwer Health/Lippincott Williams \& Wilkins; 2008 .

[12] Ridner S. Pretreatment lymphedema education and identified educational resources in breast cancer patients. Patient Education and Counseling. 2006;61(1):72-79.

[13] Ridner S, Dietrich M, Kidd N. Breast cancer treatment-related lymphedema self-care: Education, practices, symptoms, and quality of life. Supportive Care in Cancer. 2010;19(5):631-637.

[14] Roy C. Extending the Roy Adaptation Model to Meet Changing Global Needs. Nursing Science Quarterly. 2011;24(4):345-351.

[15] Sherman K, Koelmeyer L. Psychosocial predictors of adherence to lymphedema risk minimization guidelines among women with breast cancer. Psycho-Oncology. 2012;22(5):1120-1126.

[16] Abu Shosha G, Al Kalaldeh M. A critical analysis of using royâ $€^{\mathrm{TM}_{\mathrm{S}}}$ adaptation model in nursing research. International Journal of Academic Research. 2012;4(4):26-31. 